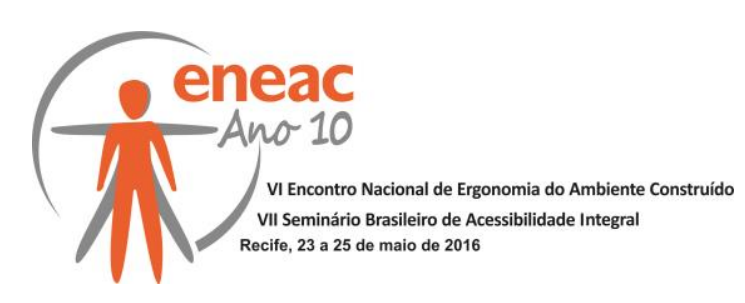

\title{
ACESSIBILIDADE EM INSTITUIÇÕES DE LONGA PERMANÊNCIA PARA IDOSOS (ILPI), COM BASE NA ANÁLISE DE INSTITUIÇÕES EM CRICIÚMA - SC
}

\author{
MILANEZE, Giovana Leticia Schindler Milaneze (1); \\ VANZIN, Tarcísio (2) \\ (1) IFSC, Mestra \\ e-mail:giovana.leticia@ifsc.edu.br \\ (2) UFSC, Doutor \\ e-mail:tvanzin@gmail.com
}

\begin{abstract}
RESUMO
Este artigo decorre sobre acessibilidade espacial em Instituições de Longa Permanência para Idosos no município de Criciúma-SC. Para pesquisa, foram utilizados diferentes métodos: pesquisa documental e bibliográfica; visitas exploratórias e observações sistemáticas. Os resultados traduzem a realidade do ambiente do idoso institucionalizado em Criciúma, submetido à projetos minimamente adaptados e/ou com projeto antigo, anterior à legislação acerca da acessibilidade. Os resultados obtidos permitiram elencar contribuições para projeto de arquitetura acessível, que podem auxiliar na concepção e melhoria dos projetos de ILPIs.
\end{abstract}

Palavras chave: acessibilidade para idosos; ILPI; acessibilidade em asilos.

\begin{abstract}
This article discusses accessibility in nursing homes in Criciuma-SC. For research, they used different methods: documentary and bibliographical research; exploratory visits and systematic observations. The results reflect the reality of the elderly institutionalized in Criciuma, underwent minimally adapted designs and / or old design, prior to legislation of accessibility. The obtained results allowed to list contributions to accessible architecture design, which can assist in the elderly institutions design and improvement of projects.
\end{abstract}

Keywords: accessibility for elderly; ILPI; accessibility in nursing homes.

\section{INTRODUÇÃO (11 PTS, NEGRITO)}

A No Brasil, histórica e culturalmente, costumava-se de manter o núcleo familiar vivendo sob o mesmo teto, desta forma os idosos vinham sendo cuidados pelos próprios familiares, independente do padrão econômico. Contudo, fatores como o crescimento urbano, e alterações sociais e econômicas, principalmente relacionadas às mulheres, que passaram a trabalhar fora, mudaram os hábitos familiares e acabaram interferindo na questão da moradia do idoso.

O aumento da longevidade e a possibilidade que se abre para que as pessoas procurem uma Instituição de Longa Permanência para Idosos (ILPI), seja para si ou para seus 


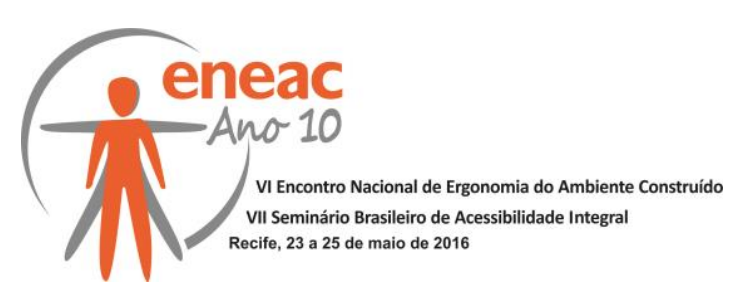

familiares, gera uma demanda por Projetos Arquitetônicos adaptados. Uma vez que as ILPIs passam a ser opção de moradia para muitos idosos, surgem preocupações a respeito desses ambientes físicos, desses espaços de convívio coletivo, no sentido de atenderem às necessidades e aos anseios de seus usuários, especialmente no que tange a acessibilidade espacial.

O assunto retro explanado foi motivador para a pesquisa já concluída e componente de uma dissertação intitulada CONTRIBUIÇÕES PARA PROJETOS DE ARQUITETURA DAS INSTITUIÇÕES DE LONGA PERMANÊNCIA PARA IDOSOS (ILPI), COM BASE NA ANÁLISE DE INSTITUIÇÕES EM CRICIÚMA - SC, submetida ao Programa de Pós Graduação em Arquitetura e Urbanismo da Universidade Federal de Santa Catarina ao fim de 2013.

Considerando a passagem de dois anos do término da pesquisa, a revisão da ABNT NBR 9050 em 2015, a falta de novidades na legislação referente ás ILPIs e principalmente a recente visita aos locais pesquisados, que permanecem sem modificações, os autores sentiram-se motivados a compartilhar este recorte da pesquisa, conforme objetivos, métodos, referenciais bibliográficos e resultados a seguir:

a) Objetivo Geral: Conhecer, avaliar e propor soluções, se necessárias, para Acessibilidade Integral nas ILPIs de Criciúma-SC

b) Objetivos específicos: Visitar, observar e anotar dados referentes à acessibilidade nas três instituições pesquisadas; Avaliar, com base em comparação com a NBR9050/2004 e referenciais teóricos selecionados, se oferecem acessibilidade necessária ao público idoso; Elaborar proposta de solução possível em casos de inconformidade.

c) Metodologia: Trata-se de pesquisa de campo exploratória, que na definição de Marconi e Lakatos (2010) consiste em conseguir informações sobre um problema para o qual se procura uma resposta ou descoberta de novos fenômenos. "Empregam-se geralmente procedimentos sistemáticos ou para obtenção de observações empíricas ou para análise de dados (ou ambas simultaneamente)". (MARCONI E LAKATOS 2010, p. 171).

A pesquisa se caracteriza como não participante e quanto ao tratamento de dados de-se de forma qualitativa. O procedimento metodológico incluiu as seguintes etapas: Constituição da parte teórico-conceitual; Pesquisa documental, para conhecimento da conjuntura do idoso no Brasil, e levantamento de legislação específica e projetos arquitetônicos; Levantamento de campo dos ambientes físicos das ILPIs; Tabulação e avaliação dos dados obtidos em campo, em conjunto com os dados teóricos pertinentes, para compor resultados;

Nesse ínterim foram utilizados diferentes métodos: pesquisa documental e bibliográfica; visitas exploratórias e observações sistemáticas.

\section{REFERENCIAL TEÓRICO E DOCUMENTAL PARA ACESSIBILIDADE E ILPIS}

Para facilitar a compreensão do trabalho, apresenta-se a seguir conteúdo referente conceituação de ILPIs, sobre as instituições estudadas e o município onde estão inseridas e o referencial teórico adotado como primordial para a pesquisa

\subsection{Sobre as ILPIs}

Não há consenso sobre o que seja uma Instituição de Longa Permanência para Idosos, no Brasil. Sua existência tem origem nos asilos, instituições inicialmente dirigidas apenas à população carente que necessitava de "abrigo" e, por isso, esse nome foi incorporado a elas. Segundo o Brasil-IPEA (2011), sua missão era a de receber idosos necessitados de 


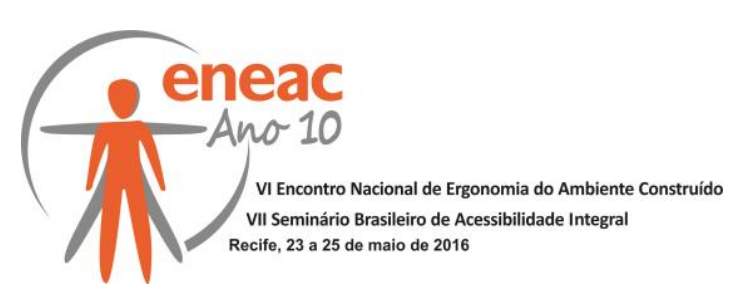

cuidados devido a perdas funcionais que lhes acarretam problemas para viverem sós ou sob cuidado constante da família.

Para Born e Boechat (2006), a ILPI é uma moradia especializada que conta com sistema contínuo de cuidados. Por ser uma moradia, deve mostrar, em seus aspectos físicos e em toda a sua programação, detalhes que lembrem uma casa, um lugar para morar, uma vida familiar. Bins Ely (2009) acrescenta que para esses ambientes, as soluções arquitetônicas são mais complexas, pois devem atender às necessidades dos idosos institucionalizados, bem como às dos seus cuidadores, que os auxiliam a cumprir suas necessidades básicas ou tarefas habituais.

\subsection{Sobre as Instituições no Município de Criciúma}

O Município de Criciúma localiza-se no extremo sul de Santa Catarina, a $200 \mathrm{~km}$ de Florianópolis. A população cresceu nos últimos 40 anos mais de 135\%, situando o município entre os mais populosos do IBGE (2010). Estima-se que em 2025 os habitantes acima de 60 anos sejam aproximadamente 20.000, segundo dados do IBGE (2010), o que bem exemplifica em porcentagem os dados estimados para o Brasil.

Existem 7 ILPIs no município de Criciúma, em 2013, no entanto apenas uma foi espacialmente planejada para tal, sendo as demais, casas adaptadas. Foram selecionadas 3, das 7 instituições, como objetos de estudo para o presente trabalho, conforme Quadro 1.

\section{Quadro 01 - ILPIs selecionadas para amostra do município de Criciúma.}

\begin{tabular}{|c|c|}
\hline Instituição & Descrição \\
\hline$\frac{1}{x-2 y}$ & $\begin{array}{l}\text { Localizada no Bairro Próspera } \\
\text { Constitui residência unifamiliar adaptada; } \\
\text { Não Certificada do Conselho Municipal do Idoso } \\
\text { Recebe } 18 \text { idosos; } \\
\text { Está em funcionamento desde novembro de } \\
2011 \text {, sendo a mais recente do município. }\end{array}$ \\
\hline 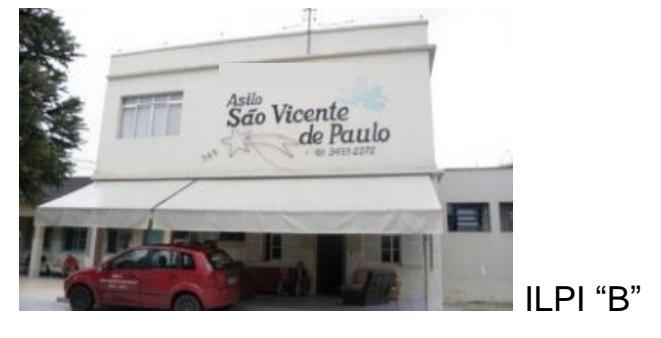 & $\begin{array}{l}\text { Localizada no Bairro Michel; } \\
\text { Constitui edificação projetada para ser uma } \\
\text { Instituição para idosos residentes; } \\
\text { Certificada do Conselho Municipal do Idoso } \\
\text { Recebe } 76 \text { idosos; } \\
\text { Está em funcionamento há mais de } 50 \text { anos. }\end{array}$ \\
\hline 瞊 & $\begin{array}{l}\text { Localizada no Bairro Cidade Mineira } \\
\text { NovaConstitui residência unifamiliar adaptada; } \\
\text { Certificada do Conselho Municipal do Idoso; } \\
\text { Recebe } 17 \text { idosos; } \\
\text { Está em funcionamento desde } 2008 \text {. }\end{array}$ \\
\hline
\end{tabular}

Fonte: Milaneze, 2013 modificado pelos autores 


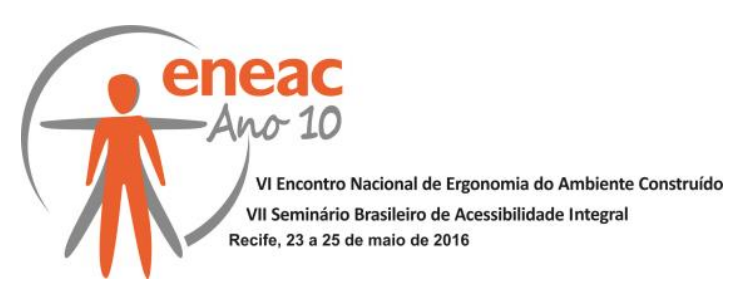

\subsection{Sobre Acessibilidade Espacial e o Idoso}

A Lei 10.098/2000 estabelece normas gerais e critérios básicos para a promoção de acessibilidade das pessoas com deficiência ou com mobilidade reduzida, mediante a supressão de barreiras e de obstáculos. Propõe a consulta dos parâmetros constantes na norma de acessibilidade - NBR 9050.

O Decreto 5.296/2004 estabelece prazo de 30 meses, que seria junho de 2007 para adequações em edificações de uso público (aquelas administradas por entidades da administração pública, direta e indireta, ou por empresas prestadoras de serviços públicos e destinadas ao público em geral).

A norma ABNT NBR 9050, revisada em 2015 que diz respeito à acessibilidade à edificações, mobiliário, espaços e equipamentos urbanos, atende a preceitos de Desenho Universal (DU) , e deve ser aplicada a todos os projetos que virem a ser elaborados, construídos, bem como as reformas e ampliações de edificações e equipamentos já existentes.

Para entender claramente o que realmente exigem as leis referentes à acessibilidade, faz-se necessário compreender alguns conceitos teóricos fundamentais, tratados a seguir:

a) Deficiência: A Organização Mundial da Saúde, através da Classificação Internacional de Funcionalidade Incapacidade e Saúde - CIF (2008) - define deficiências como problemas na função ou estrutura corporal como um desvio ou uma perda significativa. A incapacidade para alguma atividade básica (andar, subir escada, ver, ouvir, etc.) é uma consequência da deficiência, que deve ser vista de forma localizada. Dischinger, Bins Ely e Piardi (2009, p. 16) utilizam o termo deficiência para "[...] designar o problema específico de uma função ao nível fisiológico do indivíduo (por exemplo, cegueira, surdez, paralisia)".

A classificação abaixo apresentada refere-se às habilidades funcionais humanas, e, segundo Dischinger, Bins Ely e Piardi (2009), as deficiências são:

- Deficiências Físico-Motoras: que alteram a capacidade de motricidade geral do indivíduo, acarretando dificuldades, ou impossibilidade, de realizar quaisquer movimentos[...].

- Deficiências Sensoriais: são aquelas em que há perdas significativas nas capacidades dos sistemas de percepção do indivíduo

- Deficiências no sistema visual: que provocam limitações na capacidade de enxergar.

- Deficiências no sistema auditivo: [...] perda total da capacidade de perceber estímulos sonoros, ou surdez. Compromete a capacidade de comunicação pela linguagem oral.

- Deficiências no sistema de orientação/equilíbrio: Provocam alterações ou perda da capacidade de equilíbrio, afetando a manutenção da postura ereta, a percepção do movimento próprio de aceleração e a identificação dos referenciais espaciais corpóreos e ambientais.

- Deficiências Cognitivas: São aquelas que se referem às dificuldades para a compreensão e tratamento das informações recebidas (atividades mentais

- Deficiências Múltiplas: Ocorrem quando o indivíduo apresenta a associação de mais de um tipo de deficiência (DISCHINGER, BINS ELY e PIARDI, 2009, p. 18-22).

b) O Idoso: O que significa estar na "terceira idade" ou "ser idoso"? Idade funcional e idade cronológica são sinônimos? Bobbio (1997) lembra que um sexagenário é "velho" apenas no sentido burocrático, devido ao direito a uma pensão. Segundo o mesmo autor, o octogenário, salvo exceções, era considerado um velho senil, de quem não valia a pena se ocupar. Hoje, ao contrário, a velhice fisiológica se inicia próxima de oitenta anos. 


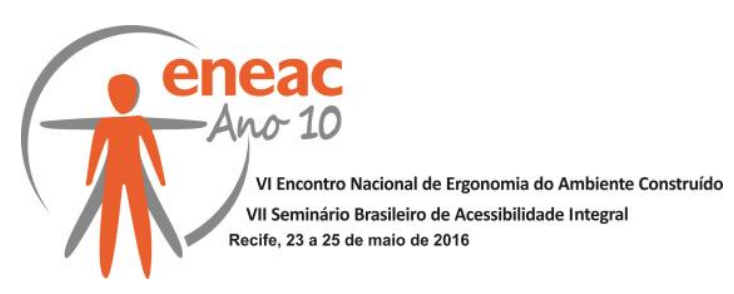

O idoso passa por uma série de possíveis alterações. As características físicas que apontam dificuldades progressivas decorrentes do envelhecimento, segundo Koncelik (19--?, apud Null e Cherry, 1996), de forma sintetizada são: alterações na Visão, como exemplos: amarelamento das lentes; opacidade das córneas; perda da percepção na intensidade das cores; menos habilidade de percepção de distâncias diferentes, como meio-fio e degraus; alterações na Audição, como exemplos: perda de audição seletiva de frequência, principalmente as mais altas, que resulta em confusão de sons e mistura de conversa com ruído de fundo; perdas na capacidade de distinguir sons de baixo volume; e, por fim, mudanças na força física, na flexibilidade e na mobilidade, exemplificada por: perda de força nos membros inferiores, que ocasiona "quedas"; perda na força do braço; necessidade de apoio para levantar-se e estabilizar o corpo (Centro de Gravidade) e transição da marcha a pé normal, para uma marcha que o empurra para a frente.

As características apresentadas corroboram o texto de Néri e Freire (2003), ao ressaltar que as possibilidades das pessoas com mais de 60 anos terem alguma deficiência é de quase $50 \%$ e também de Dischinger, Bins Ely e Piardi (2009), que ao definirem Deficiência Múltipla dão entendimento de que o idoso é uma pessoa com deficiência múltipla. Sendo assim o idoso requer ambiente com Acessibilidade Espacial.

c) Acessibilidade: Um ambiente acessível permite ao usuário utilizar o ambiente e realizar quaisquer atividades que este proporcione, de maneira confortável, fácil e segura. Para que se obtenha Acessibilidade Espacial, é necessário que se atenda aos quatro componentes da acessibilidade, em sua totalidade, que são, segundo Dischinger, Bins Ely e Piardi (2009):

? A Orientação Espacial - ligada à compreensão do espaço, permitindo assim, que os usuários reconheçam a identidade de funções do ambiente interno ou externo e desta forma definam suas estratégias de deslocamento e uso. As condições de orientação dependem das configurações arquitetônicas e dos suportes informativos adicionais existentes, como também das condições do indivíduo de tomar decisões e agir.

A Comunicação - refere-se às possibilidades de troca de informações interpessoais, ou troca de informações por meio da utilização de equipamentos de tecnologia assistiva, que permitam o acesso, a compreensão e o uso das atividades existentes.

O Deslocamento - faz referência às condições de deslocamento ao longo de percursos horizontais e verticais de forma independente, segura e confortável, sem interrupções e livre de barreiras.

O Uso - Obtido através da possibilidade de participação de todo e qualquer indivíduo nas atividades, podendo utilizar todos os ambientes e equipamentos.

\section{ANALISE E RESULTADOS SOBRE A ACESSIBILIDADE NAS ILPIS EM CRICIÚMA-SC}

A partir do levantamento realizado nas observações sistemáticas, elaborou-se um quadro de análise básica da acessibilidade nas ILPIs de Criciúma, que pode ser mais detalhado em futuras pesquisas Os resultados completos da aplicação do método de Observação, referente à acessibilidade, estão apresentados em forma de quadros.

Os vinte quadros se apresentam da seguinte maneira: Estão divididos de acordo com os Quatro Componentes da Acessibilidade Espacial; a primeira coluna descreve a característica do am biente; a segunda coluna ilustra, descreve e classifica como positivo ou negativo; a terceira coluna traz a recomendação da ABNT NBR 9050/2004, quando havia; a 


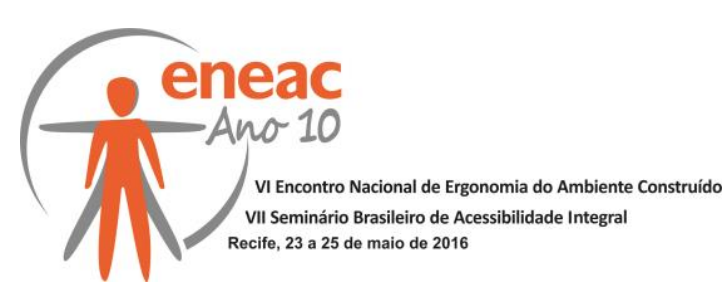

última coluna dá uma recomendação, conforme exemplificado nos Quadros das Figuras 01 à 04 a seguir:

Figura 01 - Quadro de Resultados do levantamento de acessibilidade, segundo a componentes da acessibilidade espacial Orientação

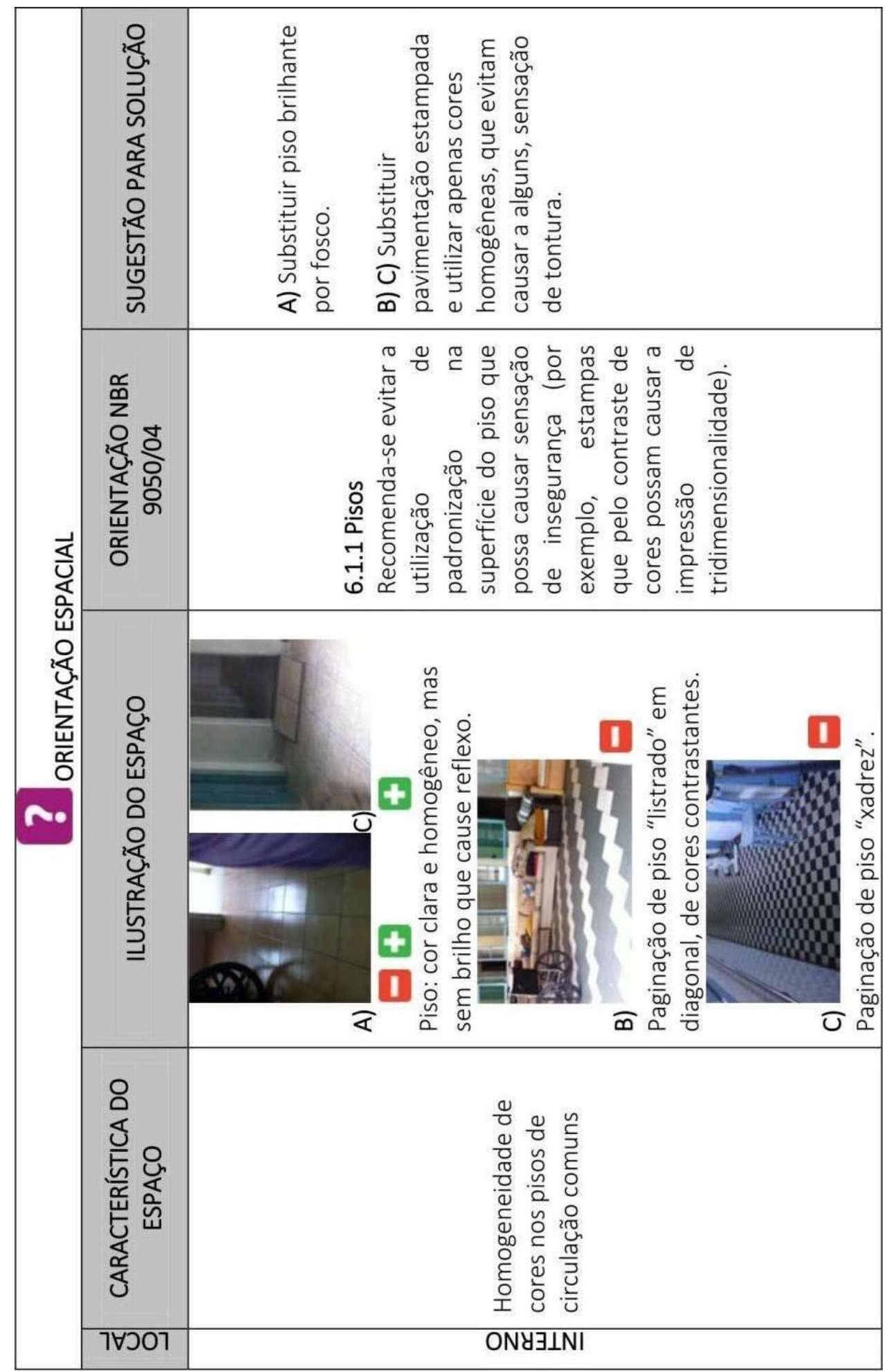

Fonte: Milaneze, 2013 


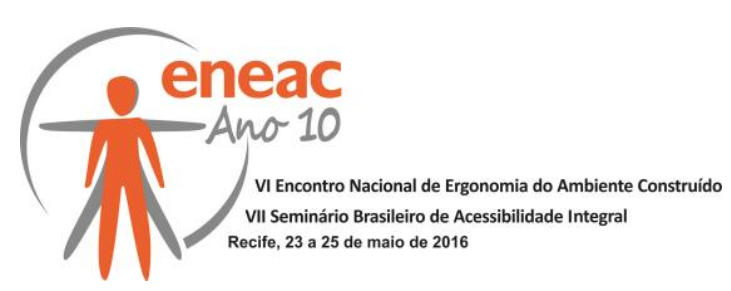

Figura 02 - Quadro de Resultados do levantamento de acessibilidade, segundo a componentes da acessibilidade espacial Comunicação

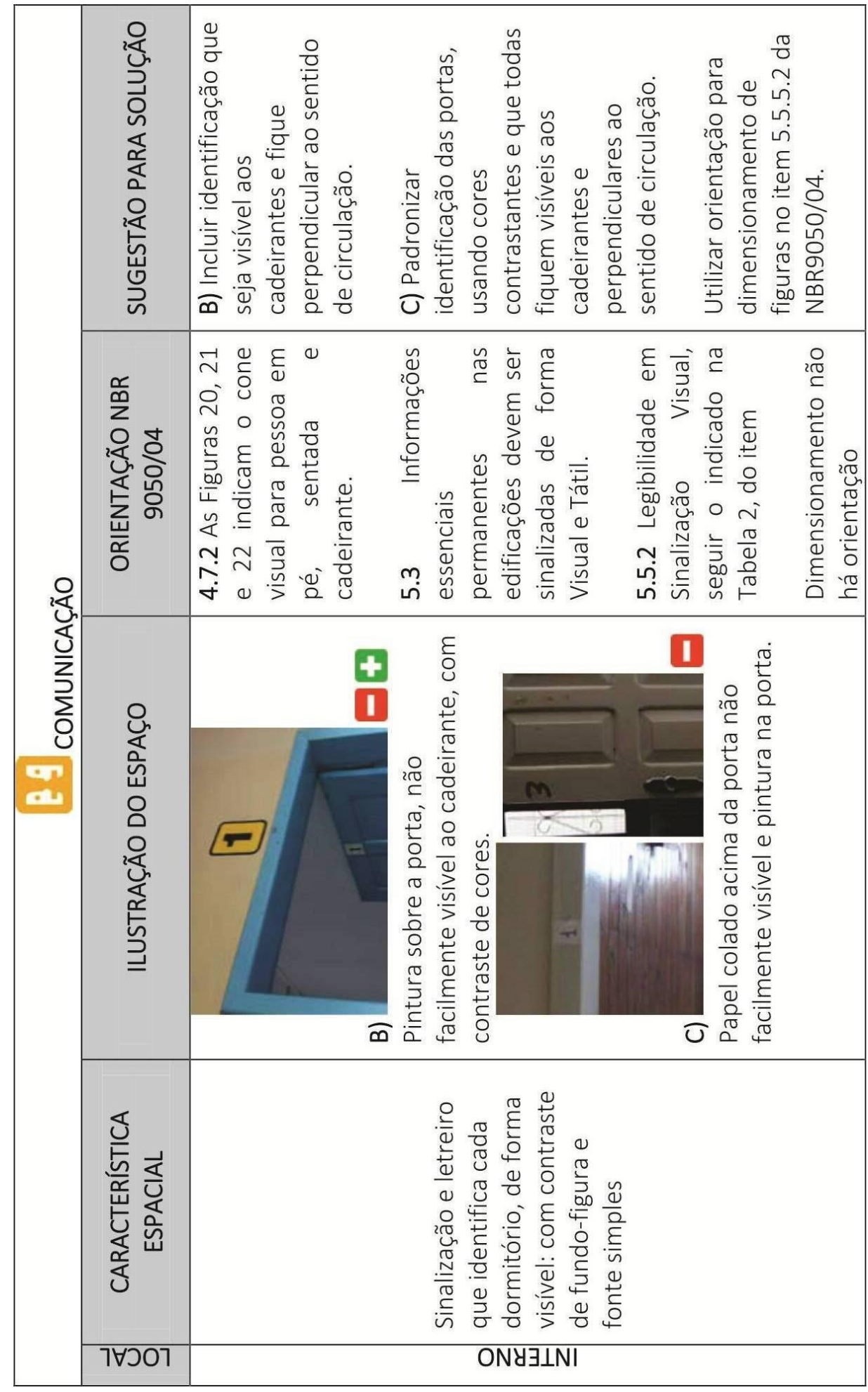

Fonte: Milaneze, 2013 


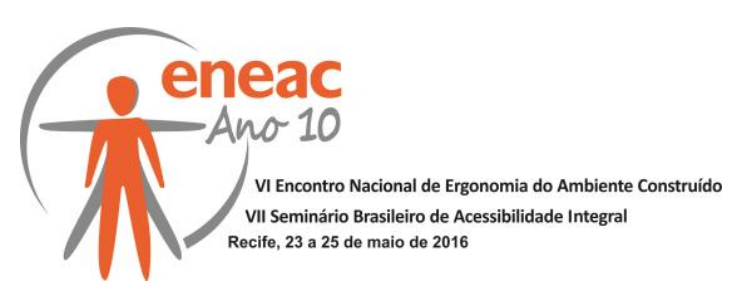

Figura 03 - Quadro de Resultados do levantamento de acessibilidade, segundo a componentes da acessibilidade espacial Deslocamento

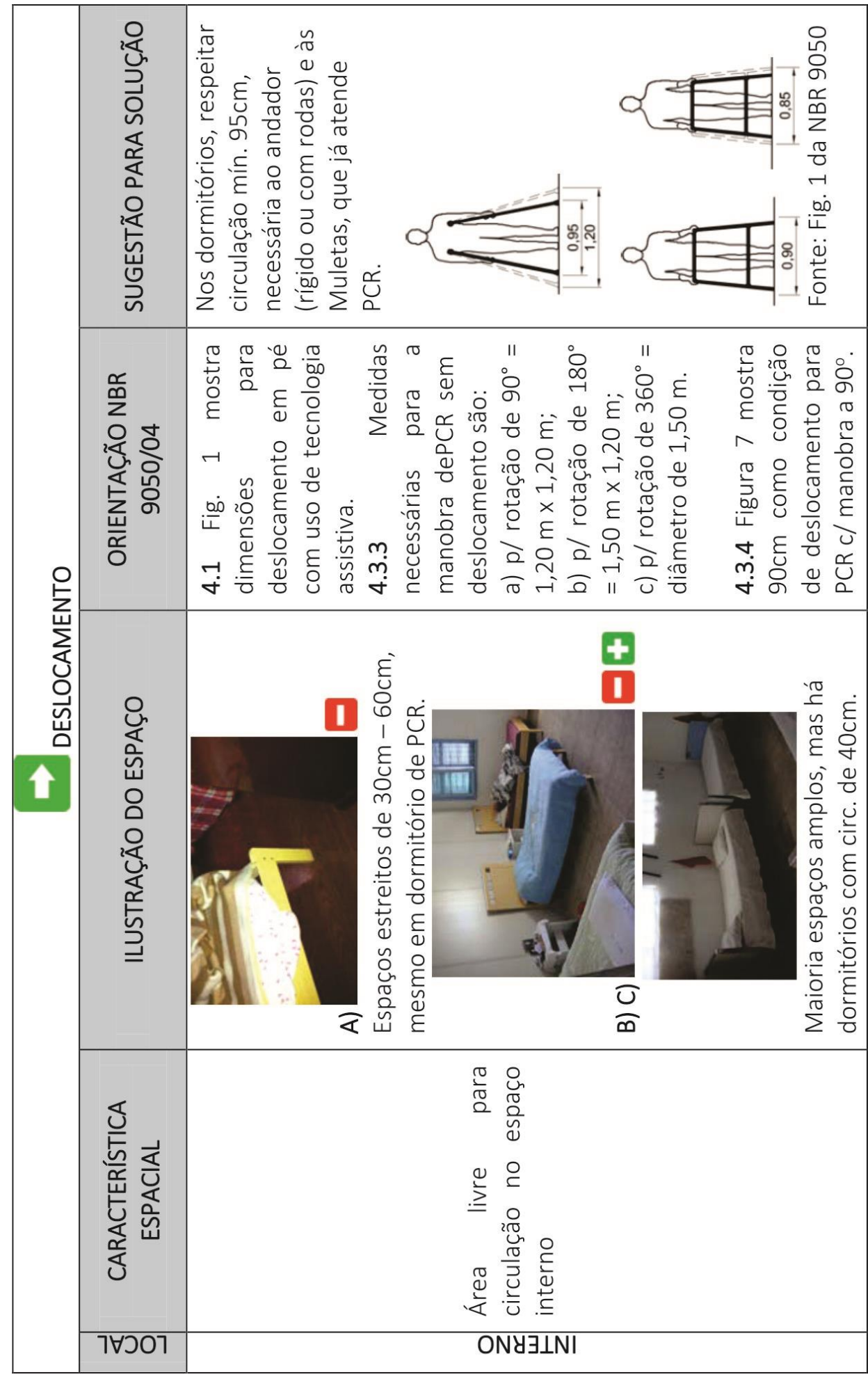

Fonte: Milaneze, 2013 


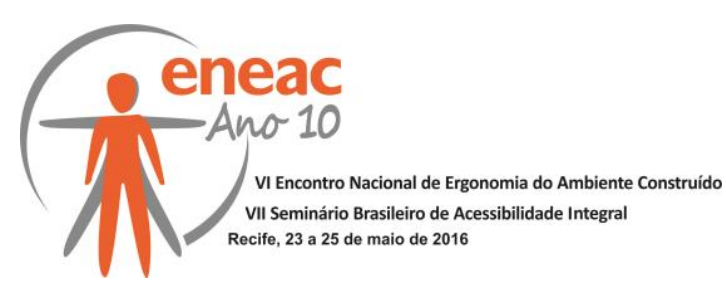

Figura 04 - Quadro de Resultados do levantamento de acessibilidade, segundo a componentes da acessibilidade espacial Uso

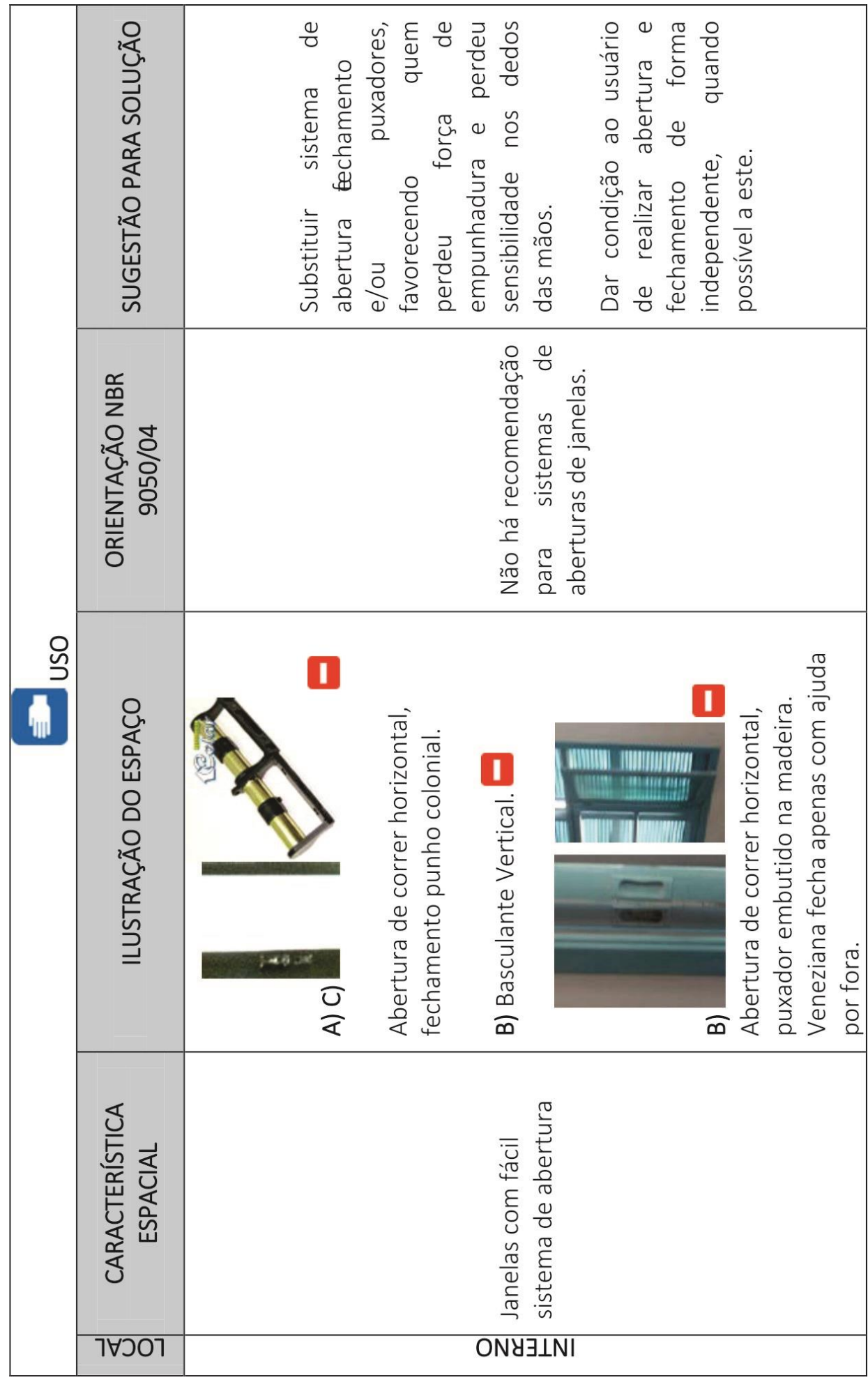

Fonte: Milaneze, 2013 


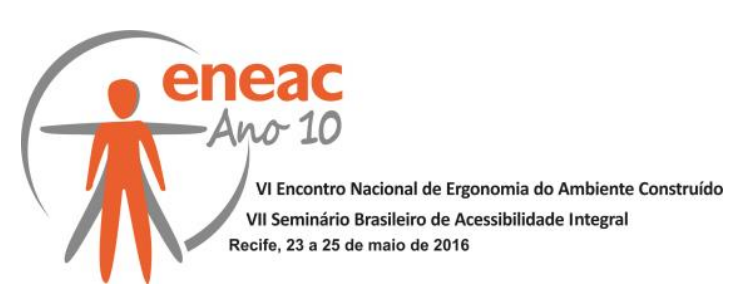

As recomendações para solução da acessibilidade nas ILPI de Criciúma, de forma parcial e sintetizada, estão relacionadas no texto que segue.

Para Orientação Espacial: O acesso do público externo à ILPI deve ter percurso claro, no traçado e pavimentação, que deve ser com piso homogêneo, opaco e com cor diferenciada dos demais, também deve ter guarda-corpo, corrimão e caminho desobstruído. A porta de entrada principal deve ser facilmente reconhecida e pode ser demarcada com uma marquise, por exemplo.

Clareza na setorização espacial: saber onde está e para onde conduzem as portas existentes no local - Identificar com setas e palavras visíveis, indicando direção para todos os espaços de interesse e/ou para os ambientes anexos.

Sinalização e letreiro que identifica a ILPI, próximos ao acesso principal - Incluir identificação que seja visível aos pedestres, inclusive nos limites do muro, quando ocupa um quarteirão. Substituir pintura e usar contraste de fundo-figura e fonte simples.

Internamente, nos corredores de dormitórios (Figura 05), devem-se demarcar portas com cores diferenciadas nos "caixilhos" e vistas; acrescentar numeração visível, de modo que fique posicionada de frente para os circundantes e fixar adereço diferenciado para cada porta, de acordo com ocupantes.

Figura 05 - Portas de corredor diferenciadas individualmente

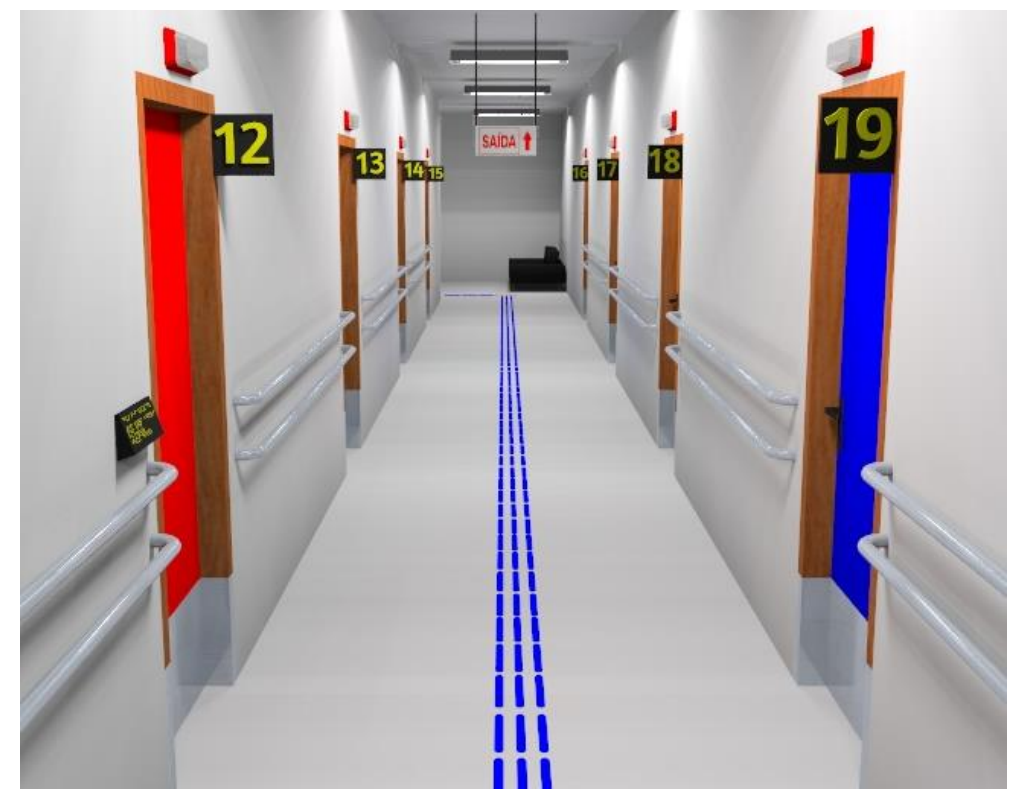

Fonte: Milaneze, 2013

Para Comunicação: Padronizar identificação das portas, usando cores contrastantes entre fundo e figura (Figura 01), de forma que todas fiquem visíveis aos cadeirantes e perpendiculares ao sentido de circulação. Utilizar orientação para dimensionamento de figuras pictóricas da NBR9050.

Para informação fixada em áreas de uso comum - Avisos, Informativos e notícias devem ser padronizados, usando cores contrastantes e visíveis, por isso devem ser fixados de acordo com cone de alcance visual que contemple a todos, e distância adequada para leitura. 


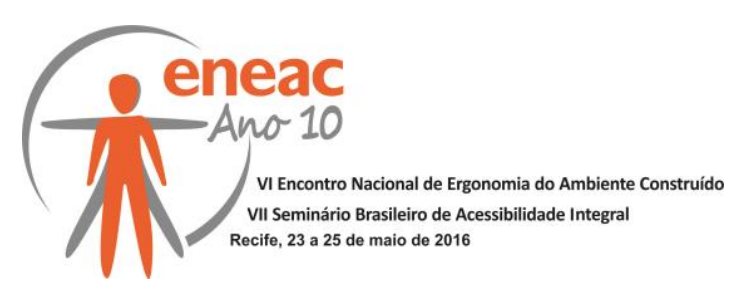

Para Deslocamento: A pavimentação na área externa, segundo NBR9050/2015, deve ter pisos com superfície regular, firme, estável e antiderrapante sob qualquer condição, que não provoque trepidação em dispositivos com rodas (cadeiras de rodas ou carrinhos de bebê). Eventuais desníveis no piso de até $5 \mathrm{~mm}$ não demandam tratamento especial, constituindo rampas.

Ainda no piso externo, a tampa da caixa, que gera obstáculo deve ser embutida no piso e a pavimentação de superfície irregular e de brita deve ser substituída em parte, configurando um percurso com piso regularizado de outro material. Prever a inclinação de piso, tipo de piso e corrimão conforme NBR 9050.

Quanto aos desníveis existentes nos pisos internos, recomenda-se nivelar todo piso, deixando rampas para vencer os desníveis apenas nas portas de acesso à edificação. Substituir revestimentos de pisos cerâmicos não classificados como antiderrapantes. Os pisos de madeira devem ser raspados, e a massa das juntas retirada e substituída por nova. Após, aplicar uma resina de secagem rápida com acabamento fosco.

Para Uso: Mesas e cadeiras para refeição com modelo e dimensionamento que favoreçam a utilização por todos. Para obesos, cadeiras com material e dimensão adequados. Segundo orienta a NBR9050/2015, a altura livre inferior de mesas deve ser no mínimo 0,73m do piso e a altura deve estar entre $0,75 \mathrm{~m}$ e $0,85 \mathrm{~m}$ do piso. Encontrou-se no refeitório o conjunto de mesa $h=80,5 \mathrm{~cm}$ e cadeira $h=43 \mathrm{~cm}$. Essa, sem pega, com pés fora da área de projeção do assento e de material pouco resistente, oferecendo riscos de queda e dificuldade de manuseio.

Nos dormitórios, substituir camas com alturas acima de $47 \mathrm{~cm}$ e abaixo de $45 \mathrm{~cm}$ e prever interruptores e botões com funcionamento em paralelo, ao alcance das camas, com teclas conforme norma e alcance máximo de $1,20 \mathrm{~m}$ para botões e $1,00 \mathrm{~m}$ para interruptor. Ainda, substituir todas as maçanetas por modelos de alavanca, que permite o uso pela maior parte dos usuários, mesmo aqueles com comprometimento dos movimentos das mãos. Instalar campainhas na lateral das cabeceiras das camas e bem próximas às camas, ou ao menos a uma das camas quando em quartos coletivos.

Substituir janelas de peitoril muito alto, por outras, que estejam ao alcance de cadeirantes, onde o sistema de abertura fique no máximo a $1,35 \mathrm{~m}$ do piso. Quanto ao layout, dispor camas e outros mobiliários de modo que não impeçam o acesso livre às janelas, permitindo ao usuário que as abra e feche.

Na área externa - Embutir grade de proteção, nos vãos das janelas na área de estar externa, já que é um obstáculo vertical na altura da cabeça. Reposicionar telefone público à altura de no máximo $1,20 \mathrm{~m}$, ainda confortável ao cadeirante.

\section{CONSIDERAÇÕES FINAIS}

São inúmeros detalhes a serem pensados pelo arquiteto ao projetar a arquitetura de uma ILPI: seus conhecimentos técnicos específicos; o atendimento das exigências legais e o entendimento sobre "quem é o usuário de idade elevada", o qual precisa de ambiente acessível, diferente da suposta pessoa jovem e saudável, para quem se costuma projetar.

No levantamento realizado nas três instituições do município de Criciúma, cumpriram-se os objetivos de conhecer, observar e anotar quesitos referentes à acessibilidade, bem como avaliar, com base em comparação com a NBR9050, referenciais teóricos selecionados, 


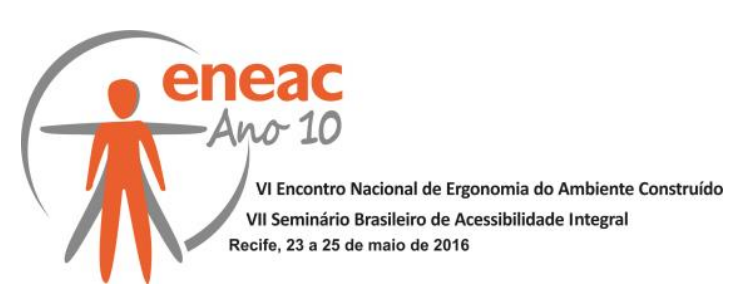

como estas ILPIs oferecem ou não, a acessibilidade necessária ao público idoso. As soluções propostas foram aqui apresentadas através do recorte de um trabalho maior, com intuito de que os problemas apontados pudessem ser resolvidos.

\section{REFERÊNCIAS BIBLIOGRÁFICAS}

BINS ELY, Vera Helena Moro. A Moradia está Adequada às Necessidades do Idoso? In: IV Worshop de Análise Ergonômica do Trabalho - UFV, jul, 2009.

BORN, Tomico, BOECHAT, Norberto S. A Qualidade dos cuidados ao Idoso Institucionalizado. In: FREITAS et al. Tratado de geriatria e gerontologia. 2 ed. Rio de Janeiro, RJ: Guanabara Koogan, 2006. p.1131-1141.

CARLI, Sandra M. M. P. Habitação adaptável ao idoso: um método para projetos residenciais. 2004. 334f. Tese (Doutorado em Arquitetura) - Faculdade de Arquitetura e Urbanismo da Universidade de São Paulo, São Paulo, 2004.

DISCHINGER, Marta; BINS ELY, Vera Helena Moro; PIARDI, Sonia Maria Demeda Groisman. Promovendo a Acessibilidade nos Edifícios Públicos. Florianópolis: 2009.

INSTITUTO BRASILEIRO DE GEOGRAFIA E ESTATÍSTICA - IBGE. Síntese de Indicadores
Sociais.

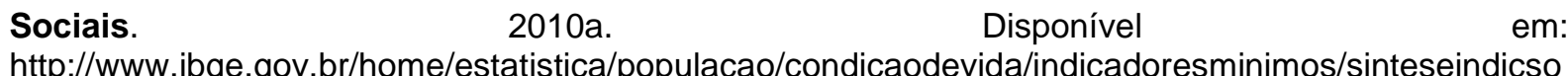
ciais2010/SIS_2010.pdf. Acesso em: 10 jan. 2011.

INSTITUTO DE PESQUISA ECONÔMICA APLICADA - IPEA. Tendências Demográficas mostradas pela PNAD 2011. In: Comunicados do IPEA o 157, 2012. Disponível em: http://www.ipea.gov.br/portal/images/stories/PDFs/comunicado/121011_comunicadoipea157.pdf.

Acessoem: 02/11/2012.

LAVILLE, Christian; DIONNE, Jean. A construção do saber: manual de metodologia da pesquisa em ciências humanas. Porto Alegre: Artmed, 1999. 340 p.

MARCONI, Marina de A.; LAKATOS, Eva M. Fundamentos de Metodologia Científica. 7 ed. São Paulo: Atlas, 2010. 297p.

MILANEZE, Giovana Letícia Schindler. Contribuições para projetos de arquitetura das instituições de longa permanência para idosos (ILPI), com base na análise de instituições em Criciúma - SC. 2013. 271 p. Dissertação (Mestrado) - Universidade Federal de Santa Catarina, Centro Tecnológico, Programa de Pós-Graduação em Arquitetura e Urbanismo, Florianópolis, 2013.

NERI, Anita Liberalesso; FREIRE, Sueli Aparecida. E por falar em boa velhice. Campinas: Papirus, 2003.

NULL, Roberta, CHERRY, Kenneth F. Universal Design: Creative Solutions for ADA Compliannce. In What is Universal Design? Cap. 2, 1996. 